\title{
O DIREITO AO ESQUECIMENTO
}

\author{
Jânio Pereira da Cunha ${ }^{1}$ \\ José Valente Neto ${ }^{2}$
}

Resumo: O artigo tem como objetivo analisar a disciplina jurídica do direito ao esquecimento no Brasil. Apesar de discussões desde o final do século passado no Brasil, principalmente por meio da televisão, o avanço da tecnologia na era digital reacendeu o debate. Foi utilizado o método de pesquisa bibliográfico e a análise de decisões. Concluiu-se que há o direito ao esquecimento no Brasil e que ele deve ser utilizado quando envolver fatos históricos, autoridades públicas e absolvição ou conclusão da pena.

Palavras-chave: Informação. Direito. Esquecimento. Memória. Liberdade.

\section{THE RIGHT TO OBLIVION}

Abstract: The article aims to analyze the legal discipline of the right to oblivion in Brazil. Despite discussions since the end of last century in Brazil, mainly through television, the advance of technology in the digital age has reignited the debate. We used the method of bibliographic research and the analysis of decisions. It was concluded that there is the right to oblivio in Brazil and that it should be used when involving historical facts, public authorities and acquittal or conclusion of the sentence.

Keywords: Information. Right. Forgetfulness. Memory. Freedom.

\section{Introdução}

Este trabalho tem como objetivo analisar a disciplina jurídica do "direito ao esquecimento" no Brasil. Em tese, os adeptos o compreendem como o direito que uma pessoa possui de não permitir que um fato, ainda que verídico, ocorrido em determinado momento, seja exposto ao público em geral de forma eterna, causando-lhe constrangimentos e, em maior grau, abalos psicológicos. Os críticos, em regra, apenas o concebem como mero apêndice a ser empregado no vácuo de "interesse público".

Almeja-se, precipuamente, obter respostas a três perguntas: i) há um direito fundamental de acesso à informação sobre fatos ocorridos no passado ou o transcurso do

\footnotetext{
${ }^{1}$ Professor do Curso de Direito e do Programa de Pós-Graduação em Direito (Mestrado Acadêmico) do Centro Universitário Christus (UNICHRISTUS). Professor do Curso de Direito da Universidade de Fortaleza (UNIFOR). Doutor em Direito Constitucional (UNIFOR). Email: janiopcunha@ hotmail.com.

${ }^{2}$ Doutorando em Direito (UFC). Mestre em Direito Constitucional (UNIFOR). Defensor Público do Estado do Ceará. Email: josevalenteneto1979@gmail.com.
} 
tempo acarreta o perecimento do direito?; ii) é compatível com a tutela constitucional das liberdades de expressão e de imprensa a invocação do "direito ao esquecimento" para impedir a divulgação ou discussão de fatos de "interesse público" precedentes em qualquer veículo de comunicação?; iii) é cabível a responsabilização civil dos veículos de comunicação, principalmente dos que utilizam a internet?

A relevância do tema reside na ausência de uma lei específica sobre o instituto e na proliferação de casos que se propagam regularmente nos meios de comunicação, sobretudo por intermédio da rede mundial de computadores. A resolução dos conflitos ficou sob a incumbência da casuística, papel desempenhado especialmente pelo Superior Tribunal de Justiça. Com efeito, com esta nomenclatura, os primeiros casos foram julgados em 2013, Recursos Especiais 1.334.097/RJ (“caso Chacina da Candelária”) e 1.335.153/RJ (“caso Aída Curi”), ambos da Quarta Turma do Superior Tribunal de Justiça. O Recurso Especial 1.316.921/RJ ("caso Xuxa"), do ano anterior, teve como substrato o Código de Defesa do Consumidor e não a Constituição Federal ou o Código Civil.

Em 2016 houve o julgamento do Agravo Interno no Recurso Especial 1.593.873-SP e, dois anos após, o acórdão no Recurso Especial 1.660.168-RJ, todos da Terceira Turma. Percebe-se que, inexistente uma decisão da Seção e nem da Corte Superior, não há uma uniformidade. Além disso, a atualidade do problema mantém-se incólume em virtude do reconhecimento de Repercussão Geral por parte do Supremo Tribunal Federal.

$\mathrm{O}$ ensaio foi dividido em três partes. Na primeira, fez-se uma digressão sobre a sociedade da informação, cuja origem ocorreu na Guerra Fria. Em sequência, procurou-se explorar os aspectos principais do dilema entre o direito ao esquecimento e o dever de memória. No último tópico, abordou-se o pensamento da jurisprudência internacional e nacional. O método de pesquisa empregado foi o bibliográfico e o exame dos acórdãos do Superior Tribunal de Justiça e do Supremo tribunal Federal.

\section{A sociedade da informação}

A sofisticação do sistema capitalista transformou-se em uma incógnita: há certeza sobre o futuro do homem? Os sociólogos e os antropólogos sempre tiveram como premissa de suas teses o vínculo direto entre as questões econômicas e não econômicas na maior parte das sociedades do Ocidente. O domínio extraeconômico passou a ser delimitado pelo econômico 
em quase todos os sentidos, do jurídico ao político. Com efeito, deve-se sempre ponderar o fato de "os fenômenos sociais e culturais não estarem a 'reboque', seguindo os fenômenos econômicos a distância: eles estão, em seu surgimento, presos na mesma rede de relações." (THOMPSON, 2012, p. 207-208)

O pilar do capitalismo é a propriedade privada dos meios de produção, cujo vetor é o trabalho assalariado formalmente livre. Ele consiste na obtenção da mais-valia por meio do trabalhador, o qual é obrigado a alienar a sua força-trabalho a quem possui o dinheiro, isto é, o proprietário. Nesta perspectiva, a sociedade foi erigida em parâmetros estritamente econômicos, calcados no lucro e na disciplina do tempo, uma vez que "as suas fundações, traves e vigas são todas feitas de material econômico. O edifício dá para o lado econômico da vida. Os prêmios e as penalidades são medidos em termos econômicos. Ascender ou retroceder significa fazer e perder dinheiro."3 (SCHUMPETER, 2003, p. 73)

A hipotética racionalização técnico-produtiva, científica e administrativa, manejada a partir da (des) regulamentação da "lógica do mercado", culmina na formação de um ethos particular e na organização de uma conduta de vida individual e coletiva. Para Anthony Giddens (1986, p. 317-318), “o capitalismo é uma sociedade de classes, e a contradição entre 'apropriação privada' e 'produção socializada' está encerrada em divisões de classes que, por sua vez, expressam interesses opostos." ${ }^{4}$ A cisão oscila em uma luta de ações e reações por meio de uma estrutura agudamente desigual que, por sua vez, não permite o desenvolvimento de todas as potencialidades e liberdades. Se, explicitamente, há um horizonte de possibilidades, implicitamente, há uma exuberância de limites.

Esse antagonismo exacerbado constrói propositalmente um novo padrão cuja vulgata propaga a ideia de uma neutralidade do direito, como se sua fonte difusora fosse alheia ao complexo processo de (re) produção econômica. Conforme a síntese de Michel Miaille (1989, p. 68), "uma reflexão científica tem de ir mais longe e dizer-nos que tipo de direito produz tal tipo de sociedade e porque é que esse direito corresponde a essa sociedade.” As ideologias, principalmente as jurídicas, têm concebido, em cada época e em cada lugar, representações míticas que disseminam uma retórica normativa e camuflam a essência do sistema predominante.

\footnotetext{
${ }^{3}$ No original: "Its foundations, beams and beacons are all made of economic material. The building faces toward the economic side of life. Prizes and penalties are measured in pecuniary terms. Going up and going down means making and losing money."

${ }^{4}$ No original: "Capitalism is a class society and the contradiction between 'private appropriation' and 'socialized production' is locked into class divisions which in turn express opposing interests".
} 
O acúmulo de capital, ou seja, o lucro, bem como a sua contrapartida, o risco, são consequências das condições heterogêneas inerentes à sociedade estratificada do "ter" e do “não ter”. A Revolução Industrial e as revoluções tecnológicas subsequentes, fomentadas a partir do colonialismo ultramarino inglês, conduziram a transferência do processo de produção do artesanato e da manufatura para a fábrica, a qual possibilitou uma ampliação vertiginosa da produção e, por conseguinte, da concentração de pecúnia em benefício de pequenos grupos, formando-se os monopólios e os oligopólios. Após a industrialização, a "acumulação de capital e a expansão econômica adquiriram um impulso próprio."5 (DOBB, 1962, p. 35-36)

As interpretações sobre os desdobramentos deste fenômeno são variadas. Desde a indústria de algodão, com as técnicas de fiação e tecelagem em grande escala, até a eletrônica e inteligência artificial (computação, robôs, energia nuclear), passando pelo uso do motor à combustão, o mundo passou por transformações em todos os níveis. Em tese, segundo Niall Ferguson (1999, v. I; 2011, v. II), a industrialização poderia ser dividida em duas etapas. A primeira, entre 1798 e 1848 , e a segunda, a partir de 1849 , a qual passou a ser remodelada pelas revoluções tecnológicas.

A deflagração da industrialização pode ser definida como modernização simples ou ortodoxa, ao passo que a evolução das tecnologias pode ser redefinida como modernização reflexiva. Segundo Ulrich Beck (1997, p. 12), “este novo estágio, em que o progresso pode se transformar em autodestruição, em que um tipo de modernização destrói outro e o modifica, é o que eu chamo de etapa da modernização reflexiva." No bojo de mudanças radicais, a produção de riquezas se acentuou, quase sempre, concomitantemente à geração de riscos. Ressalte-se que

precisamente en el trato con los riesgos resultan muchas diferenciaciones y
conflictos sociales nuevos. Éstos ya no siguen el esquema de la sociedad de clases.
Surgen sobre todo de la doble faz de los riesgos en la sociedad de mercado
desarrollada: los riesgos son aquí no sólo riesgos, sino también oportunidades de
mercado. De ahí que precisamente con el despliegue de la sociedad del riesgo se
desplieguen los contrastes entre quienes están afectados por los riesgos y quienes se
benefician de ellos. De una manera similar crece el significado social y político del
saber, y por tanto el poder sobre los medios que lo configuran (la ciencia y la
investigación) y lo di funden (los medios de comunicación de masas). En este
sentido, la sociedad del riesgo también es la sociedad de la ciencia, de los medios y
de la información. En ella se abren asínuevos contrastes entre quienes producen las
definiciones del riesgo y quienes las consumen. Estas tensiones entre la supresión
del riesgo y el negocio, la producción y el consumo de las definiciones del riesgo,

\footnotetext{
${ }^{5}$ No original: “[...] capital accumulation and economic expansion acquired a momentum of their own”.
} 
atraviesan todos los ámbitos de actuación social. Aquí se encuentran fuentes esenciales para las «luchas de definición» por la medida, el grado y la urgencia de los riesgos. El aprovechamiento de los riesgos al expanderse el mercado favorece una oscilación general entre ocultar y desvelar los riesgos, con la consecuencia de que al final ya nadie sabe si el «problema» no será la «solución»o al revés, quién se beneficia de qué, dónde se descubren u ocultan autorías mediante conjeturas causales y si lo que se dice de los riesgos no será expresión de una dramaturgia política que en realidad pretende algo completamente distinto. (BECK, 2002, p. 5253)

O epílogo do século XX projetou a gênese da "sociedade da hiperinformação", nova etapa tecnológica que se ramificou por todos os aspectos da humanidade. Em sua disputa com a ex - União das Repúblicas Socialistas Soviéticas (URSS), durante a Guerra Fria, os Estados Unidos da América (EUA), temendo ataques em seu sistema de defesa, "passaram a investir na criação de um instrumento de comunicação livre de centros de comandos específicos, a fim de que a transmissão de dados nunca fosse paralisada por eventual ataque nuclear." (CASTELLS, 2016, p. 101). Neste particular, Anthony Giddens (2012, p. 517) adverte que

\begin{abstract}
a internet se originou durante o período da Guerra Fria antes de 1989. A 'rede' foi desenvolvida a partir de um sistema usado no Pentágono, o quartel-general do exército norte-americano, desde 1969. Esse sistema foi chamado inicialmente de rede ARPA, sigla da Advanced Research Projects Agency do Pentágono. A ARPA visava permitir que cientistas trabalhando em contratos militares em diferentes partes dos Estados Unidos reunissem seus recursos e compartilhassem o caro equipamento que usavam. Quase como uma reflexão tardia, seus criadores pensaram em um meio para também enviar mensagens - e, assim, nasceu o correio eletrônico, o email. Até o começo da década de 1980, a internet do Pentágono consistia em 500 computadores, todos localizados em laboratórios militares e departamentos de ciência da computação em universidades. Outras pessoas nas universidades então começaram a aprender e a usar o sistema para seus próprios fins. Em 1987, a internet havia se expandido e compreendia 28 mil servidores, em muitas universidades e laboratórios de pesquisa diferentes.
\end{abstract}

Com efeito, a era digital consumou o processo de globalização. Consoante Peter Burke (2012, p. 277), "se definirmos globalização em termos de relações cada vez mais próximas entre os povos de diferentes partes do mundo, é claro que o processo vem ocorrendo há milhares de anos, por mais que se tenha acelerado nas últimas duas ou três décadas." Os avanços alteraram totalmente a face da comunicação das informações, sons ou imagens à distância. Esvaiu-se a noção de tempo e de espaço. Para Iona Stupariu (2015, p. 6),

as últimas décadas têm sido o mercado mais impactante pela invenção e a rápida ascensão de novos dispositivos tecnológicos, assim como a expansão da internet. Essas novas tecnologias têm desafiado significativamente o pensamento e as reações das pessoas, tanto na sociedade em geral quanto na esfera particular do direito, exigindo uma resposta imediata e forte. Como consequência, surgiram conceitos radicalmente novos como a vigilância eletrônica, a propriedade virtual, a moeda virtual e a existência de pessoas virtuais, novos debates como a responsabilidade dos provedores, a eficácia na proteção dos direitos humanos on-line no contexto do choque entre o direito à privacidade e liberdade de expressão, o acesso à internet 
como direito humano nasceram, ou substituindo completamente os clássicos, ou reformulando os antigos. ${ }^{6}$

Em que pesem as vantagens, Zygmunt Bauman (2013, p. 113) captou o fenômeno como "modernidade líquida". Segundo o seu parecer, parecem evidentes e graves os riscos à privacidade, "emanados da ampla abertura da arena pública aos interesses privados [e também o inverso], e sua gradual mas incessante transformação numa espécie de teatro de variedades dedicado à diversão ligeira.” Sobre este fenômeno, oportunas as indagações de Asa Briggs e Peter Burke (2002, p. 368-369):

Toda esa actividad, casi inconcebible en una aldea, tenía una dimensión global que planteaba interesantes problemas éticos y, en especial, legales. (...). Pero además de las cuestiones de derecho, había otras de política, que, como el argumento jurídico, giraban en torno a la pregunta: ¿se puede o se debe controlar internet? Y en caso afirmativo, ¿de qué manera? ¿Debería el autocontrol asumir, mediante cuerpos intermediarios, el lugar del control estatal?

Em sintonia, a advertência de Ivana Có Galdino Crivelli (2019, p. 257), segundo a qual "a intimidade e a privacidade do ser humano devem ser protegidas contra a devassa voltada a agraciar o interesse do público por bisbilhotices." É neste complexo contexto de reflexões e fluidez que se insere o debate entre a liberdade de expressão e o direito à privacidade, ambos com previsão constitucional.

\section{O direito ao esquecimento e/ou dever de memória}

$\mathrm{O}$ direito ao esquecimento, também conhecido como the right to be forgotten, the right to oblivion, droit à l'oubli, derecho al olvido ou Recht auf Vergessenerden ou diritto all'oblio, voltou ao debate com ênfase na última década, apesar de ser um tema objeto de discussões antigas. "Os que se posicionam contra o aceite do direito ao esquecimento argumentam que a base de qualquer democracia respalda-se na proteção dos direitos de expressão, de informação e na proteção de uma imprensa livre." (ABÍLIO; MENDONÇA, 2018, p. 78) Segundo François Ost (2005, p. 160-161),

\footnotetext{
${ }^{6}$ No original: "The latest decades have been most strickingly market by the invention and rapidly ascension of new technological devices, as well as the expansion of internet. These new technologies have significantly challenge the thinking and reactions of people, both in the society at large as well as in the particular sphere of law, requiring a prompt and strong response. As a consequence, radically new concepts such as electronic surveillance, virtual property, virtual currency and the existence of virtual persons have emerged moreover, new debates such as the liability of ISP's, the efficacy in protecting human rights online in the context of the clash between the right to privacy and freedom of expression, the access to internet as - human right have been born, either replacing classical ones completely, or reshaping old ones."
} 
o direito ao esquecimento, consagrado pela jurisprudência, surge mais claramente como uma das múltiplas facetas do direito a respeito da vida privada. Uma vez que, personagem pública ou não, fomos lançados diante da cena e colocados sob os projetores da atualidade - muitas vezes é preciso dizer, uma atualidade penal -, temos o direito, depois de determinado tempo, a sermos deixados em paz e a recair no esquecimento e no anonimato, do qual jamais queríamos ter saído.

No Recurso Especial 1.335.153/RJ (BRASIL, 2013, on-line), o Min. Luís Felipe Salomão enumerou os argumentos mais relevantes que se mantém firmes na trincheira em benefício do dever de memória. De um modo geral, o acórdão entendeu que o acolhimento do chamado direito ao esquecimento constituiria um atentado à liberdade de expressão e de imprensa, o direito de fazer desaparecer as informações que retratam uma pessoa significa perda da própria história, o que vale dizer que o direito ao esquecimento afronta o direito à memória de toda a sociedade e o direito ao esquecimento teria o condão de fazer desaparecer registros sobre crimes e criminosos perversos, que entraram para a história social, policial e judiciária, informações de inegável interesse público.

Em endosso do direito às informações, Marcos Ehrhardt Júnior, Danyelle Nunes e Uly Porto (2017, p. 67) defendem que "discuti-las é essencial para a formação de convicções pessoais e preferências e, em conseqüência, para a realização de escolhas conscientes." Consoante o entendimento de Daniel Sarmento (2016, p. 200-201), em consulta contratada pela Globo Comunicação e Participações S/A, consignou:

\begin{abstract}
Afirmar que há um direito fundamental a não ser lembrado, contra a sua vontade, por fatos passados constrangedores ou desagradáveis, é atribuir este direito a todas as pessoas. Porém, em praticamente todos os acontecimentos existem aspectos cuja recordação pode causar embaraço ou sofrimento para alguém. Em todos os crimes há um culpado; em todas as batalhas e disputas existe um perdedor. As narrativas das vivências humanas revelam as imperfeições, erros e fragilidades das pessoas, e é natural que estas prefiram que as suas falhas caiam no olvido. Porém, erigir este desejo à condição de direito fundamental é o mesmo que impedir o conhecimento da História. Com essa afirmação, não se está sustentando a tese de que o direito à informação sobre fatos passados prevalece sempre e incondicionalmente sobre outros direitos da personalidade, como a privacidade ou a honra. $\mathrm{O}$ que se está afirmando é que a passagem do tempo não retira a importância e o interesse público das informações, porque a História é essencial para a sociedade. E o argumento torna-se ainda mais irresistível em países que tem uma trajetória histórica de violação de direitos humanos, em que a superação de traumas e feridas clama não pelo esquecimento do passado, mas pelo fortalecimento da memória coletiva.
\end{abstract}

O principal argumento consiste, portanto, no direito à liberdade de expressão. Em adendo, em uma tentativa tosca de conciliação, a fim de permitir o exercício do direito ao esquecimento, o interditam porventura existente o interesse público na divulgação daquela informação. É curioso observar que constitucionalistas, civilistas e penalistas já se manifestaram em várias oportunidades, com inclinação para a máxima restrição do direito ao 
esquecimento, mas uma questão restou inexplorada. Nesta tomada de posições, é óbvio que tanto o passado escravocrata quanto o regime militar que precedeu a Constituição de 1988 contribuem para a manifestação em favor da liberdade quase irrestrita e da ojeriza à censura. São valores intrínsecos à democracia.

Todavia, o quadro que se delineia reclama ultrapassar essa etapa. Nesta perspectiva, algumas indagações são, concomitantemente, oportunas e instigantes: i) quem comanda os principais veículos de comunicação? ii) o que é "interesse público"?; iii) em regra, quais são as pessoas cujas informações despertam interesse da mídia? Com a liberdade de imprensa, os canais passaram a ser jocosamente chamados de "quarto poder".

Todavia, o protagonismo do Ministério Público nas ações coletivas de um modo geral e a previsão constitucional de direitos e garantias semelhantes ao Poder Judiciário, o elevaram a "quarto poder" e a mass media, por conseguinte, a um "quinto poder" da República. Um jornalismo parcial e antiético é nefasto em qualquer regime político, particularmente nas democracias liberais que assomaram no constitucionalismo latino-americano nas décadas de 80 e 90 pretéritas e que sucumbem vertiginosamente no limiar do século XXI.

Além disso, é irrefutável o poder econômico das empresas e conglomerados. A "rede" serve como a principal interface para o "comércio eletrônico", transações comerciais realizadas online e que movimenta bilhões de dólares em segundos. Esse espaço é usado com o único objetivo: angariar lucros vultosos. Mesmo quando se transmite a ideia de uma filantropia ou neutralidade da informação, o propósito é legitimar a atividade econômica e permanecer na posição mais cômoda do sistema capitalista.

Os meios de comunicação de massa transformaram-se em corporações extremamente rentáveis e que manipulam o "interesse público", conceito jurídico indeterminado. As informações são repassadas por redatores, editores-chefe, jornalistas e empresários. Há um filtro e um leque de opções para que os dados sejam processados em determinada direção ou readequados em benefício de determinados interesse. Outro ponto ventilado pelos opositores do "direito ao esquecimento", subsidiário do direito de liberdade de expressão, reside na vedação da censura. Entretanto, não se trata de censura propriamente dita. A título de ilustração, se uma informação veiculada há dez anos no Google deixar de ser transmitida, já houve divulgação. Haveria, então, uma censura posterior? É inegável que foi assegurada a liberdade de expressão. 
O problema assume uma dimensão superior quando se trata de pessoas absolvidas no âmbito criminal. Qual seria o interesse público na preservação das informações que um réu respondeu a um processo penal recluso e que, na sentença, foi comprovada a ausência de culpa? Nenhum. Nestas hipóteses, o único interesse, vil, é manter os robustos lucros de programas e sítios que exploram, irresponsavelmente, o sensacionalismo que grassa na mídia no Brasil.

\section{3. $O$ direito ao esquecimento na jurisprudência}

No Recurso Especial 1.316.921/RJ (BRASIL, STJ, 2012, on-line), “caso Xuxa", tratava-se de demanda proposta por Maria da Graça Xuxa Meneghel, apresentadora de programas infantis e infanto-juvenis, contra a empresa Google Brasil Internet Ltda. O objetivo era a supressão dos mecanismos de busca de todo e qualquer resultado relativo à busca com base na expressão "Xuxa pedófila" ou qualquer outra expressão que vinculasse o seu nome a qualquer espécie de crime.

A decisão foi no sentido de que não têm responsabilidade objetiva os provedores de pesquisa via internet pelo conteúdo do resultado das buscas realizadas por seus usuários, porquanto não se pode considerar o dano moral um risco inerente à atividade dos provedores de pesquisa, na medida em que as atividades desenvolvidas pelos provedores de serviços na internet não são de risco por sua própria natureza e, portanto, não implicam riscos para direitos de terceiros maior que os riscos de qualquer atividade comercial.

Não há defeito nos serviços dos provedores de pesquisa via internet por não exercerem o controle prévio das buscas realizadas por seus usuários, ainda que seus mecanismos de busca facilitem o acesso e a consequente divulgação de páginas cujo conteúdo seja ilegal, tendo em vista que, se a página possui conteúdo ilícito, cabe ao ofendido adotar medidas tendentes à sua própria supressão, com o que estarão, automaticamente, excluídas dos resultados de busca virtual dos sites de pesquisa.

Não é cabível a imposição de astreintes na hipótese em que o Tribunal a quo impôs a provedor de pesquisa a obrigação de excluir dos resultados de pesquisa de seu site de busca determinadas imagens, dispensada a indicação do URL das páginas onde essas imagens estariam inseridas, porquanto a determinação é tecnicamente impossível de ser cumprida, bem como, mesmo que se quisesse adequar os termos da decisão, objetivando a sua 
exequibilidade, exigindo da vítima a indicação dos URL's, isso implicaria na ausência de interesse de agir.

No Recurso Especial 1.334.097/RJ (BRASIL, STJ, 2013, on-line), “caso Chacina da Candelária", o caso chegou aos graus superiores depois que um serralheiro foi retratado pelo programa Linha Direta - Justiça como um dos envolvidos na chacina da Candelária, na qual oito jovens que dormiam na rua foram mortos no Rio, em 1993. O problema é que, quando o programa foi ao ar, em 2006, ele já havia sido absolvido da acusação por um tribunal do júri. Anos após ser inocentado de todas as acusações, o homem foi retratado no programa Linha Direta, da TV Globo.

Ele ajuizou ação pedindo danos morais por violação ao direito ao esquecimento, e obteve decisões favoráveis no Tribunal de Justiça do Rio de Janeiro e pela $4^{\text {a }}$ Turma do Superior Tribunal de Justiça. O homem, que negara entrevista à atração, disse que foi prejudicado com a exposição, perdendo "seu direito à paz, [ao] anonimato e [à] privacidade pessoal". Ele relatou que não conseguiu mais emprego e teve de se mudar do local onde vivia, para não ser morto por "justiceiros".

Já a Globo disse que o programa tratou de um acontecimento relevante e de interesse público, limitando-se a narrar fatos. O direito ao esquecimento, para a emissora, sobrepujaria seu direito de informar. Segundo a defesa, ocultar o nome do autor do processo e de outros inocentados pelo crime "seria o mesmo que deixar o programa jornalístico sem qualquer lógica, pois um dos mais relevantes aspectos que envolveram o crime foi justamente a conturbada e incompetente investigação promovida pela policia”.

A Rede Globo pretendia levar o caso ao STF sob a alegação de que houve violação à liberdade de expressão artística e de comunicação, liberdade de pensamento, direito de resposta, direito ao acesso à informação e proteção à intimidade e à privacidade. $\mathrm{O}$ recurso apontava também que foram desrespeitados os princípios da produção e programação de emissoras de televisão e a impossibilidade de restrição à manifestação do pensamento.

No REsp. 1.335.153/RJ (BRASIL, STJ, 2013, on-line), “caso Aída Curi”, tratava-se de uma ação de indenização por danos materiais, morais e por violação de direito de imagem apresentada por quatro irmãos de Aída Curi, vítima de homicídio, em 1958, no Rio de Janeiro. O objetivo era impedir que a Globo, por intermédio do Programa "Linha Direta" reproduzisse e reconstituísse, décadas depois, o fato. Segundo a decisão do STJ, as vítimas de crimes e seus familiares têm direito ao esquecimento, se assim desejarem, consistente em não 
se submeterem a desnecessárias lembranças de fatos passados que lhes causaram, por si, inesquecíveis feridas.

Caso contrário, chegar-se-ia à antipática e desumana solução de reconhecer esse direito ao ofensor - o que está relacionado com sua ressocialização - e retirá-lo dos ofendidos, permitindo que os canais de informação se enriqueçam mediante a indefinida exploração das desgraças privadas pelas quais passaram. Todavia, no caso de familiares de vítimas de crimes passados, que só querem esquecer a dor pela qual passaram em determinado momento da vida, há uma infeliz constatação: na medida em que o tempo passa e se vai adquirindo um "direito ao esquecimento", na contramão, a dor vai diminuindo, de modo que, relembrar o fato trágico da vida, a depender do tempo transcorrido, embora possa gerar desconforto, não causa o mesmo abalo de antes.

Nesse contexto, deve-se analisar, em cada caso concreto, como foi utilizada a imagem da vítima, para que se verifique se houve, efetivamente, alguma violação aos direitos dos familiares. Isso porque nem toda veiculação não consentida da imagem é indevida ou digna de reparação, sendo frequentes os casos em que a imagem da pessoa é publicada de forma respeitosa e sem nenhum viés comercial ou econômico. Assim, quando a imagem não for, em si, o cerne da publicação, e também não revele situação vexatória ou degradante, a solução dada pelo STJ será o reconhecimento da inexistência do dever de indenizar.

O caso encontra-se no âmbito do Supremo Tribunal Federal, conforme Agravo em Recurso Extraordinário 833.248 (BRASIL, STF, 2015, on-line), posteriormente substituído pelo RE 1.010.606/RJ e submetido, desde 2014, ao procedimento da Repercussão Geral. Observe-se que, até então, o STJ negava a responsabilidade dos provedores de pesquisa em relação a conteúdos postados por terceiros e facilmente disponíveis mediante mecanismos de buscas. Vários pedidos de desindexação de links com o desiderato de impedir ou dificultar o acesso à internet forma negados.

No Agravo Interno no Recurso Especial 1.593.873-SP (BRASIL, 2016, STJ, on-line), tratava-se de demanda proposta contra o Google Brasil Internet para que houvesse a exclusão, em caráter definitivo, dos mecanismos de buscas de links com acesso a imagens íntimas da autora. Os provedores de pesquisa não podem ser obrigados a eliminar do seu sistema os resultados derivados da busca de determinado termo ou expressão, tampouco os resultados que apontem para uma foto ou texto específico, independentemente da indicação da página onde este estiver inserido. 
Além disso, entendeu-se que no Brasil inexiste disposição legal específica imposto a responsabilidade pela desindexação, apesar da Lei 12.965/14, conhecida como "Marco Civil da Internet", e que era inaplicável à hipótese a decisão do Tribunal de Justiça da União Europeia no caso Google vs. Agência Espanhola de Proteção de Dados e Mario Costeja. De acordo com o entendimento de Mário Viola de Azevedo Cunha e Gabriel Itagiba (2016, p. 637),

no caso contra o Google Spain e Google Inc., o ECJ reconheceu a existência de um direito a ser esquecido que autoriza sujeitos de dados solicitam que o Google exclua de sua pesquisa links do mecanismo que aparecem como resultado de pesquisas. Tal decisão provocou reações vivas, colocando em lados diferentes defensores da liberdade de expressão e aqueles que defendem para privacidade.

No Recurso Especial 1.660.168-RJ (BRASIL, STJ, 2018, on-line), uma promotora de justiça propôs ação contra as empresas Google Brasil Internet Ltda, Yahoo do Brasil Internet Ltda e Microsoft Informática Ltda, a fim de obter a implantação de filtro por palavra-chave com o objetivo de evitar a associação do seu nome a notícias envolvendo suposta fraude em concurso para a magistratura estadual no ano de 2007.

O fato foi objeto de investigação no âmbito do Conselho Nacional de Justiça e não foram encontradas provas suficientes para subsidiar a ocorrência do ilícito. Na decisão, o STJ registrou que o fato referido já conta com mais de uma década, e ainda hoje os resultados de busca apontam como mais relevantes as notícias a ela relacionadas, como se, ao longo desta década, não houvesse nenhum desdobramento da notícia nem fatos novos relacionados ao nome da autora.

Quanto ao assunto, a jurisprudência desta Corte Superior tem entendimento reiterado no sentido de afastar a responsabilidade de buscadores da internet pelos resultados de busca apresentados, reconhecendo a impossibilidade de lhe atribuir a função de censor e impondo ao prejudicado o direcionamento de sua pretensão contra os provedores de conteúdo, responsáveis pela disponibilização do conteúdo indevido na internet. Há, todavia, circunstâncias excepcionalíssimas em que é necessária a intervenção pontual do Poder Judiciário para fazer cessar o vínculo criado, nos bancos de dados dos provedores de busca, entre dados pessoais e resultados da busca, que não guardam relevância para interesse público à informação, seja pelo conteúdo eminentemente privado, seja pelo decurso do tempo.

Essa é a essência do direito ao esquecimento: não se trata de efetivamente apagar o passado, mas de permitir que a pessoa envolvida siga sua vida com razoável anonimato, não 
sendo o fato desabonador corriqueiramente rememorado e perenizado por sistemas automatizados de busca. Por outro vértice, aqueles que quiserem ter acesso a informações relativas a fraudes em concurso público, não terão seu direito de acesso impedido, porquanto as fontes que mencionam inclusive o nome da autora permanecerão acessíveis. Contudo, sua busca deverá conter critérios relativos a esse conteúdo, seja em conjunto com o nome da autora, seja de forma autônoma.

É nítida a evolução da jurisprudência do Superior Tribunal de Justiça entre 2012 e 2018. Antes, sem exceção. Depois, com exceção. Em um primeiro momento, a jurisprudência do STJ é digna de aplausos, haja vista que o mérito deve ser julgado à luz do caso concreto, ou seja, inadmitir excepcionalidades significa generalizar e ampliar o risco de cometimento de injustiças. No arcabouço das peculiaridades, é possível consignar os crimes genuinamente históricos e as autoridades públicas.

Em segundo lugar, em sede de crítica construtiva, o acórdão mais recente do Superior Tribunal de Justiça, apesar de criar uma solução conciliadora entre o direito à informação e o direito à privacidade, contrariou frontalmente a Lei 12.965/2014, mais precisamente o art. 19, $\S 3^{\circ}$, segundo o qual as causas que versem sobre ressarcimento por danos decorrentes de conteúdos disponibilizados na internet relacionados à honra, à reputação ou a direitos de personalidade, bem como sobre a indisponibilização desses conteúdos por provedores de aplicações de internet, poderão ser apresentadas perante os juizados especiais. Isto é, a própria Lei prevê literalmente a hipótese de indisponibilização de conteúdo pelos provedores de internet.

\section{Considerações finais.}

A procrastinação do Supremo Tribunal Federal em apreciar a tese do direito ao esquecimento no Agravo em Recurso Extraordinário 833.248, posteriormente substituído pelo RE 1.010.606/RJ, submetido à Repercussão desde 2014, mantém em evidência o debate. É importante ressaltar que vários contextos do problema são conclusões homogêneas entre os adeptos e os críticos. É inquestionável a liberdade de expressão e a vedação de censura, principalmente em face das condições históricas do Brasil, o qual padeceu de mais de três séculos de escravidão e de sucessivos golpes de Estado, os quais geralmente são executados mediante opressão e restrição das liberdades públicas. 
Neste particular, é possível afirmar que há um direito fundamental de acesso à informação sobre fatos históricos, mesmo aqueles consumados em passado remoto. Além disso, não se pode invocar o direito ao esquecimento quando os fatos envolvem autoridades públicas, haja vista que há presunção de interesse público. Há casos em que a nota pública é ostensiva. Entretanto, há hipóteses, não raras, em que a percepção da característica elencada pelos opositores é duvidosa.

O caso típico reside na preservação de informações a respeito de um processo penal no qual, após ampla divulgação na mídia durante o transcurso processual, houve absolvição. Qual o interesse público? Nenhum. Em menor grau, mas também guarnecido o direito, encontra-se a situação do condenado em processo criminal que teve reabilitação. Ou seja, se o próprio sistema já chancelou formalmente a ressocialização, qual o interesse da pulverizada opinião pública no Brasil em prosseguir com uma quase persecução penal ou ostracismo social?

Ademais, são discutíveis a geração das informações em virtude dos conglomerados econômicos e dos vultosos lucros que circulam em suas contas bancárias. A internet transformou-se no cenário de transações bilionárias. É cediço que espaços, websites, são objeto de contratos de locação, e que, na maioria das vezes, as informações têm como propósito interesses particulares. Dentro desta conjuntura, é cabível a responsabilização civil dos veículos de comunicação, principalmente dos que utilizam a internet.

\section{Referências.}

ABÍLIO, Adriana Galvão Moura; MENDONÇA, Christopher. O Brasil está preparado para o direito ao esquecimento? Revista de Direito Constitucional e Internacional, São Paulo, v. 105, a. 26, p. 77-95, jan.-fev. 2018.

BAUMAN, Zygmunt. Danos colaterais: desigualdades sociais numa era global. Tradução de Carlos Alberto Medeiros. Rio de Janeiro: Zahar, 2013, p. 113.

BECK, Ulrich. A reinvenção da política: rumo a uma teoria da modernização reflexiva. In: BECK, Ulrich; GIDDENS, Anthony; LASH, Scott. Modernização reflexiva: política, tradição e estética na ordem social moderna. Tradução de Magda Lopes. São Paulo: Unesp, 1997. p. 11-71.

La sociedad del riesgo. Hacia uma nueva modernidad. Traducción de Jorge Navarro, Daniel Jiménez e Maria Rosa Borrás. Barcelona: Paidós, 2002. 
BRASIL. Superior Tribunal de Justiça. Agravo Interno no Recurso Especial 1.593.873/SP. Rel. Min. Nancy Andrighi. Diário de Justiça, Brasília, 17 nov. 2016.

BRASIL. Superior Tribunal de Justiça. Recurso Especial 1.316.921/RJ. Rel. Min. Nancy Andrighi. Diário de Justiça, Brasília, 29 jun. 2012.

BRASIL. Superior Tribunal de Justiça. Recurso Especial 1.334.097/RJ. Rel. Min. Luís Felipe Salomão. Diário de Justiça, Brasília, 10 set. 2013.

BRASIL. Superior Tribunal de Justiça. Recurso Especial 1.335.153/RJ. Rel. Min. Luis Felipe Salomão. Diário de Justiça, Brasília, 10 set. 2013.

BRASIL. Superior Tribunal de Justiça. Recurso Especial 1.660.168/RJ. Rel. Min. Nancy Andrighi. Diário de Justiça, Brasília, 5 jun. 2018.

BRASIL. Supremo Tribunal Federal. Agravo em Recurso Extraordinário 833.248 RG/RJ. Rel. Min. Dias Toffoli. Diário de Justiça, Brasília, 20 fev. 2015.

BRIGGS, Asa; BURKE, Peter. De Gutenberg a internet: una historia social de los medios de comunicación. Traducción de Marco Aurelio Galmarini. Madrid: Taurus historia, 2002.

BURKE, Peter. História e teoria social. 3. ed. Tradução de Klauss Brandini Gerhardt, Roneide Venâncio Majer e Roberto Ferreira Leal. São Paulo: Editora Unesp, 2012.

CASTELLS, Manuel. A sociedade em rede: a era da informação: economia, sociedade e cultura. 17. ed. São Paulo: Paz e Terra, 2016.

CRIVELLI, Ivana Có Galdino. Intimidade e privacidade na era da informação. In: CORREIA, Atalá; CAPUCHO, Fábio Jun (coords.). Direitos da personalidade: a contribuição de Silmara J. A. Chinellato. Barueri, SP: Manole, 2019. p. 256-273.

CUNHA, Mário Viola de Azevedo; ITAGIBA, Gabriel. Between privacy, freedom of information and freedom of expression: Is there a right to be forgotten in Brazil? Computer law \& security review, n. 32, p. 634-641, 2016.

DOBB, Maurice. Capitalism yesterday and today. New York: Monthly Review Press, 1962.

EHRHARDT JÚNIOR, Marcos Augusto de Albuquerque; NUNES, Danyelle Rodrigues de Melo; PORTO, Uly de Carvalho Rocha. Direito ao esquecimento segundo o STJ e sua incompatibilidade com o sistema constitucional brasileiro. Revista de Informação Legislativa, Brasília, a. 54, n. 213, p. 63-80, jan.-mar. 2017.

FERGUSON, Niall. The house of Rothschild: money's prophets, 1798-1848. New York: Penguin Books, 1999. v. I.

The house of Rothschild: The world's banker, 1849-1999. New York: Penguin Books, 2011. v. II. 
GIDDENS, Anthony. Sociologia. 6. ed. Tradução de Ronaldo Cataldo Costa. Porto Alegre: Penso, 2012.

The constitution of society. Cambridge, UK: Polity Press, 1986.

MIAILLE, Michel. Introdução crítica ao direito. 2. ed. Lisboa: Editorial Estampa, 1989.

OST, François. O tempo do direito. Tradução de Élcio Fernandes. Bauru, SP: Edusc, 2005.

SARMENTO, Daniel. Parecer - Liberdades comunicativas e "direito ao esquecimento" na ordem constitucional brasileira. Revista Brasileira de Direito Civil, São Paulo, v. 7, p. 190232, jan.-mar. 2016.

SCHUMPETER, Joseph A. Capitalism, socialism and democracy. London, New York: Routledge, 2003.

THOMPSON, Edward Palmer. Modos de dominação e Revolução na Inglaterra. In: NEGRO, Antonio Luigi; SILVA, Sergio (orgs.). As peculiaridades dos ingleses e outros artigos/Edward Palmer Thompson. Tradução de Fernando Teixeira da Silva. 2. ed. Campinas, SP: Editora da Unicamp, 2012. p. 203-225. 